\title{
雪の壁，天井材としての利用 \\ Utilization of Snow as Wall or Ceiling Element
}

\author{
○正 媚山政良(室工大) \\ 学 佐々木賢知（室工大院） \\ KOBIYAMA Masayoshi and SASAKI Masanori, Muroran Institute of Technology, Mizumoto Muroran
}

From a viewpoint of software side, the snow is one of the mysterious materials for almost passengers visiting snowy country from hardly snowfall area. When they encounter with the snow, they may be felt the impulse to touch the snow, to realize coldness and to be charmed by the snow. There are many voices that they would like to have this mysterious experience even during midsummer. In order to respond to those needs, the authors planed to construct a small space enclosed by snow walls, and developed a technique that prevents snowy dissolution under hot condition with the aid of refrigerator. With this technology, a project that makes a small space enclosed with snow walls in midsummer was carried out with the member of the Sapporo Commerce-and-Industry Meeting in this summer, and we also have been enjoyed.

Key words: mysterious snow, hot midsummer, small space, wall of snow, prevention of snowy dissolution, refrigerator

1.はじめに 環境保全, 省桝ギーの追い風を受け, いわ ゆる“利雪”が急速に定着しつつある. また，雪は資源とし ての新しい一面をも誢かせつつあり, 新しい利雪分野の開拓 が推し進められて来ている. 雪を师面から見ると, 雪のほと んど降らない地域の人たちにとって, 雪は一つの神秘である. 雪国を訪ねる多くの観光客にとって, 雪は “触って冷たさを 実感し，その神秘に魅了されたい”ものの一つである. でき れば, この体験を真夏にも・..とと声は多い. 雪を用いて小 空間を作り, “文化”を行うものとしては，横手の「かまくら」 が有名である.このかまくらの築造技術とその洗練された形 状には完成された感がある，しかし，残念ながら，このかま くら，冬期限定である．夏にかまくらを作るプ听外を札幌 商工会のメバーとこの夏, 実施し, 楽しんだ.このプ听ェ外 を“雪のピラミ帅 (雪的金字塔)”と呼んでいる.

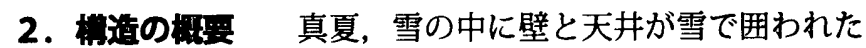
小空間 (展示室) を作る.この小空間の中に, 毎時 20 名程度 の “屋外からの訪問者”をおおよそ 10 日間受け入れる. 炎天 下では雪は解ける. 雪を壁材, 天井材として強度を保つため

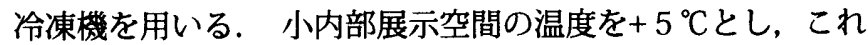
に面する壁, 天井の雪温を強度を保てる・ $2^{\circ} \mathrm{C}$ 以下とする. 雪 で覆った壁，天井の構造を図 1 に示す．雪を冷やすため低温 の不凍液を流す冷却管を配し，また，雪を支持するため执パ ンド外を用いる．また，同時に内部空間の面の上には霜を成 長させ，内部空間を光に映える非日常的なものとする. 図 1 の冷却管より下側には外部からの侵入熱を熱抵抗として軽減 させる約 $30 \mathrm{~cm}$ の雪（被り雪）と融解熱により軽減させる約

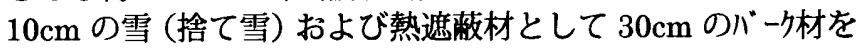
積む (図 9 参照)。なお, 冷凍機は研究室所有の $7.5 \mathrm{~kW}$ (蒸 発温度 $-20^{\circ} \mathrm{C}$, 凝縮温度 $40^{\circ} \mathrm{C}$, 定格冷凍能力 $12750 \mathrm{kcal} / \mathrm{h}$. ブ ラ们温度 $-10^{\circ} \mathrm{C}$ での実能力 $9000 \mathrm{kcal} / \mathrm{h}$ (=実測值)）を使用する.

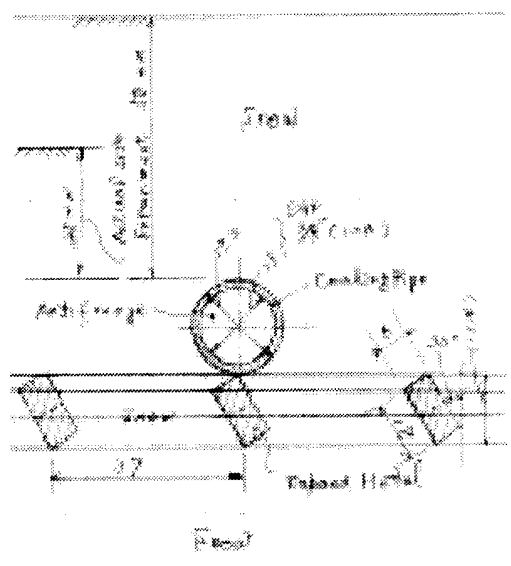

図 1 雪で覆つ た壁, 天 井の構造

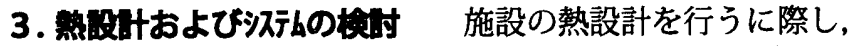
(1)捨て雪の厚さ，(2)被り雪の厚さ，(3)内部の壁，天井表面か

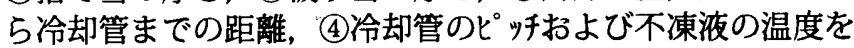
決める必要がある. (1)に関しては, 展示期間を 10 日とすると $100 \mathrm{~mm}$ と推測される. (3)は, 内部構造物が壁, 天井を通し 透けて見えない厚さを実験により確認し， $25 \mathrm{~mm}$ とした。

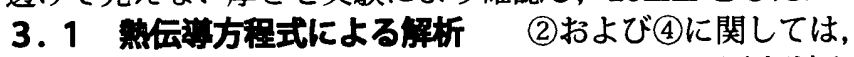
次のように定常 2 次元の熱伝導方程式をシュシッの図式解法を 基礎とした差分法により数値解析を行い, その結果を実験と 比較し妥当性を確認し, 熱設計の資料とした。なお, 执パン ド灿および冷却管の存在を無視し解析を行った. 座標系を図 2 に示す. 図 2 に記入してある寸法は, 最終的に採用した設 計值に係わる数量である.

$$
\frac{\partial^{2} t}{\partial x^{2}}+\frac{\partial^{2} t}{\partial y^{2}}=o \cdot \cdots \cdot(1)
$$

境界条件としては, 状況に応じ等温条件, 断熱条件（対称面 および断熱面）を採る. 図3に差分格子を示す．この差分格 子を用い式(1)を差分近似すると次式を得る.

$$
\begin{aligned}
t_{1, j}= & {\left[\mathrm{C}_{1} t_{1}+1, \mathrm{j}+\mathrm{C}_{2} t_{1-1, \mathrm{j}}+\mathrm{C}_{3} t_{\mathrm{t}, \mathrm{j}+1}+\mathrm{C}_{4} t_{\mathrm{t}, \mathrm{j}-1}\right] } \\
& /\left[\mathrm{C}_{1}+\mathrm{C}_{2}+\mathrm{C}_{3}+\mathrm{C}_{4}\right] \cdots \cdot \cdots \cdot(2)
\end{aligned}
$$

ここで, $\mathrm{C}_{1}=1 /\left(\Delta x_{\mathrm{P}} \cdot \Delta x_{\mathrm{PM}}\right) \quad \mathrm{C}_{2}=1 /\left(\Delta x_{\mathrm{M}} \cdot \Delta x_{\mathrm{PM}}\right)$ $\mathrm{C}_{3}=1 /\left(\Delta y_{\mathrm{P}} \cdot \Delta y_{\mathrm{PM}}\right) \quad \mathrm{C}_{4}=1 /\left(\Delta y_{\mathrm{M}} \cdot \Delta y_{\mathrm{PM}}\right)$ なお, 空気の雪相当厚さ $\delta[\mathrm{m}]$ は $\delta=\lambda / \alpha$ として求める.

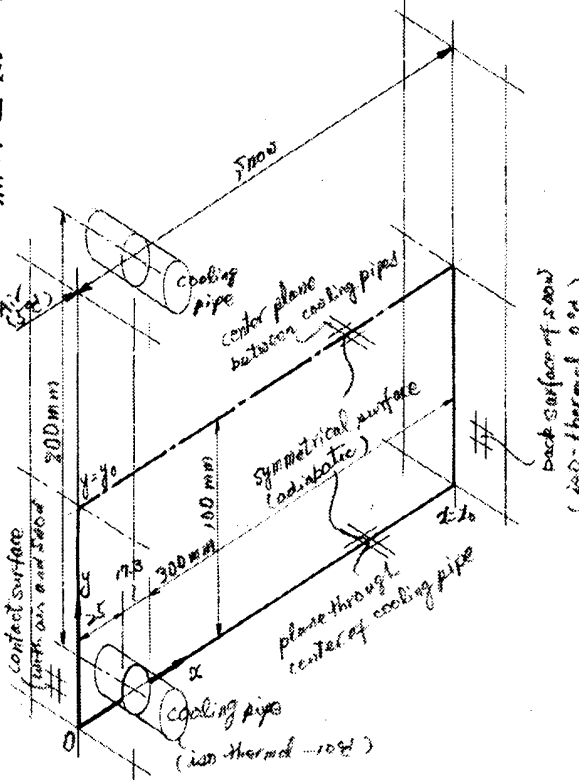

図 2 座標系

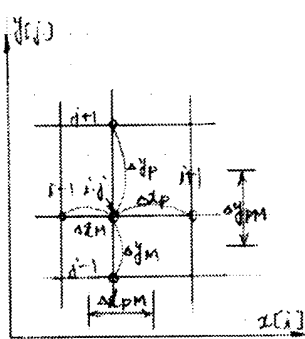

図 3 差分格子 


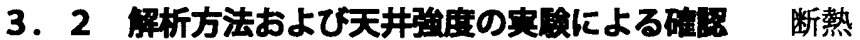

材に囲まれた図 4 に示す容器に雪を詰め, 冷凍機により冷や された入り口温度 $-10.5^{\circ} \mathrm{C}$, 出口温度 $-10.9^{\circ} \mathrm{C}$ の不凍液 (I千レング 归ール $67 \%$, 水 $33 \%$ ）を冷却管（SGP 3/8” 10A）を通し流 し，雪を凍結させた．流量は $45.1 \mathrm{~L} / \mathrm{h}$ とした．凍結管の下に は，雪を支える执パ 外㶴 (図 1 参照)を配してある.また, 雪の上の空間の温度を $6.5^{\circ} \mathrm{C}$ 維持するため, ア列风板上に温調 器付のリボ ンータ-を設置してある. 低温庫に保存したざらめ雪 を 4 月下旬に取り出し, うっすらと解けかけた状態で, 密度 $0.55 \mathrm{ton} / \mathrm{m}^{3}$ となるよう均しながら詰めた．不凍液を流し雪の 凍結を開始し，おおよそ3日間でほぼ定常状態となった．な お, 図 4の丸文字で示す 4 ケ所の温度を T 型熱電対により連 続し測定した.ほぼ定常となった状態では，2本の凍結管の 中間部の雪は約 $9 \mathrm{~mm}$ 解けており, 定常に至るまでに融解一一 部内部へ浸透-再凍結されていることが分かった. この実 験の状態での諸量を解析に取り込んだ温度分布の結果を実験 値と比較し図 5 に示す. 同図(a)は雪の熱伝導率を $\lambda=0.55$ $\left[\mathrm{kcal} / \mathrm{mh}^{\circ} \mathrm{C}\right]$ とした場合の結果であり, 同図(b)は $\lambda=0.90$ とし た場合である. 底の断熱材に近い部分の温度(4)は $\lambda=0.55$ の 場合に実験値と解析の結果は良く一致しており, 空気側(2), (3)では $\lambda=0.90$ とした場合に良い一致が認められた.なお, 実験による伝熱量は $15.0 \mathrm{kcal} / \mathrm{h}$ であり, 不凍液の温度測定の 最小值が $0.1{ }^{\circ} \mathrm{C}$ でることを勘案すると, 雪の熱伝導率を $\lambda$ $=0.90\left[\mathrm{kcal} / \mathrm{mh}^{\circ} \mathrm{C}\right]$ とした場合の解析結果 $12.8 \mathrm{kcal} / \mathrm{h}$ とほぼ一 致している.これらのことから, 融解一部内部へ浸透-再凍 結を受けるこの系では，雪の中に密度の分布が形成されてい ることが推測され，これを認めると, 本解析手法は現象をか なり良く表すことができるものと考えられる. ちなみに，こ の熱伝導率から雪の密度を推測すると断熱材に近い部分では $0.60 \mathrm{ton} / \mathrm{m}^{3}$ 程度であり, また, 空気側では融解·再凍結の影響 が大きく表れ 0.75 ton $/ \mathrm{m}^{3}$ 程度になっていると考えられる. この結果から, 安全を見込み, 温度分布の熱設計では $\lambda$ $=0.55\left[\mathrm{kcal} / \mathrm{mh}^{\circ} \mathrm{C}\right]$ とし, 熱負荷の熱設計では $\lambda=0.90$ を採る.

また，図 4 の実験装置を上下反転し不凍液を流しながら放 置したが, 雪は冷却管に支持されたIキスパンド姼にに分な力で 付着し落下することはなかった. 雪が空気と接する部分の雪 温が- $2^{\circ} \mathrm{C}$ 以下 (不凍液の温度約 $-10^{\circ} \mathrm{C}$ ) で, 雪の厚さが $50 \mathrm{~mm}$, 凍結管のピッが $300 \mathrm{~mm}$ 以下であれば，天井材として利用が 可能であることが分かった. なお, 準備期間の短いイベンでは, 凍結管のピ炖を狭くし定常までの時間を短縮する必要がある.

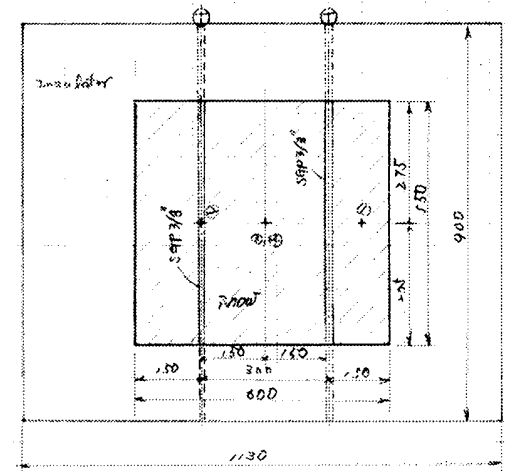

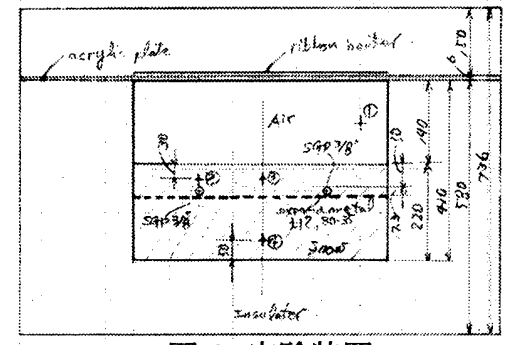

図 4 実験装置

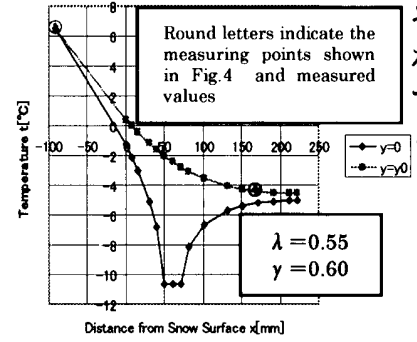

図 5 (a) 計算值 と実験值の比較

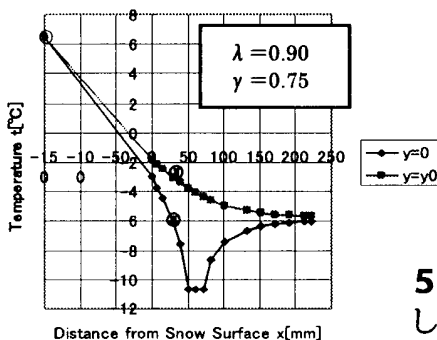

図 $5(b)$

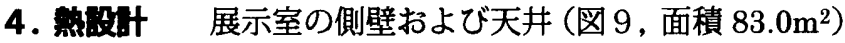
に雪を貼り付け，これを $7.5 \mathrm{~kW}$ の冷凍機で維持することを考 える. なお, 調整室 (通路, $12 \mathrm{~m}^{2}$ ) の冷房も同時に行う.

4. 1 什結果 内部の壁, 天井表面から冷却管までの 雪の厚さを $25 \mathrm{~mm} ， 3.2$ の結果をもとに冷却管のピッチを $200 \mathrm{~mm}$ とする. 被り雪の厚さに関しては，これをパラメータと し全熱負荷を計算した結果, $30 \mathrm{~cm}$ とした場合に冷凍機の能 力の範囲内に収まることが分かった．また，内部空間の温度 を $+5{ }^{\circ} \mathrm{C}$, 雪表面の熱伝達率を $\alpha=6.0\left[\mathrm{kcal} / \mathrm{m}^{2} \mathrm{~h}{ }^{\circ} \mathrm{C}\right]$, 雪の背 面 (バーク材側) の温度を氷の融点である $0{ }^{\circ} \mathrm{C}$, 冷却 (不凍液)

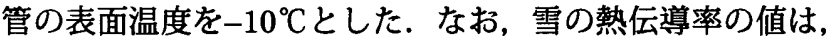
3.2において記述の通りである. この時の雪内部の温 度を図 6 に，また，雪の表面温度を図 7 に示す。雪の表面温 度はほぼ- $2{ }^{\circ} \mathrm{C}$ 以下で, 天井材としての強度を維持できる覀囲 である．熱負荷の分布を図 8 に示す．雪表面から空気への熱 流束の平均值は, $q_{\mathrm{m} 1}=56.0\left[\mathrm{kcal} / \mathrm{m}^{2} \mathrm{~h}\right], 0^{\circ} \mathrm{C}$ の雪から被り雪 への熱流束は $q_{\mathrm{m}} \mathrm{M}=-17.8$ である.

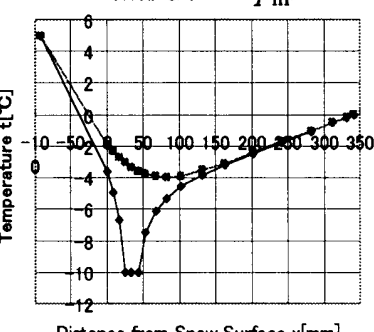

Distance from Snow Surface $\times[\mathrm{mm}]$

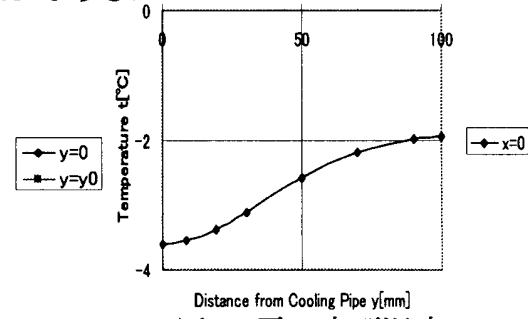

図 7 雪の表面温度
図 6 雪内部の温度

図 8 熱負荷の分布

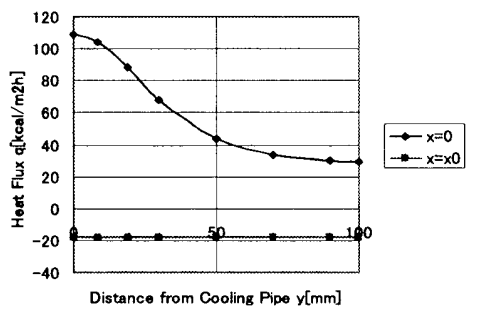

4. 2 帮収支雪の壁を維持するのに必要な冷熱量は,

$(56.0+17.8)[\mathrm{kcal} / \mathrm{m} 2 \mathrm{~h}] \times 83.0\left[\mathrm{~m}^{2}\right]=6126[\mathrm{kcal} / \mathrm{h}]$ となり，こ れを, 床からの侵入熱 $(365[\mathrm{kcal} / \mathrm{h}])$, 入場者の発熱 $(220[\mathrm{kcal} /$ 人 $\mathrm{h}] \times 20[$ 人 $]=4400[\mathrm{kcal} / \mathrm{h}])$ ，換気 $(427[\mathrm{kcal} / \mathrm{h}])$, 照明 $(372[\mathrm{kcal} / \mathrm{h}])$ およびポンプの発熱 $(645[\mathrm{kcal} / \mathrm{h}])$ で賄うと, その差は-83[kcal/h]の僅少となり，室温はほぼ設定した $5{ }^{\circ} \mathrm{C}$ を保つことができる.また，調整室の熱負荷は，2440[kcal/h] であり, 冷凍機に要求される冷熱出力は, $8566[\mathrm{kcal} / \mathrm{h}]$ とな ，実冷凍能力 $9000[\mathrm{kcal} / \mathrm{h}]$ の範囲内となっている.

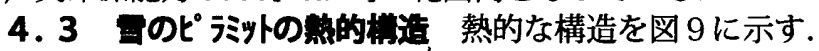

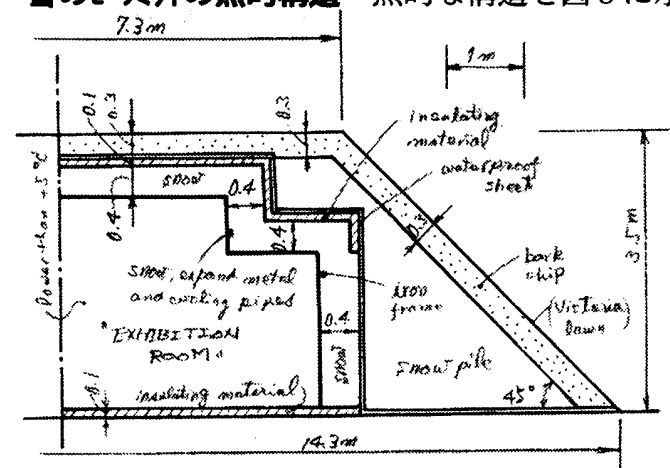

図 9 雪のピラミットの熱的構造

5. おわりに 2004 年 7 月 8 日より 10 日まで, 図 9 に示 した寸法に近い“雪のピラミ゙ト”を札幌市大通り公園 $2 丁$ 目に おいて製作し，11 日から 19 日まで一般開放した。おおよそ 1 万 3000 人の入場者を集め, 好評であり, 我々も楽しんだ. 